\title{
Assessment and Comparison of Dental Anxiety by Measuring Physiological, Psychological and Immune Responses in Pediatric Patients Undergoing Noninvasive Dental Treatment
}

\author{
Kavita Dhinsa ${ }^{1}$, Sonali Saha ${ }^{2}$, Gaurav Singh ${ }^{3}$, Gurpreet Dhinsa ${ }^{4}$, Dhritanayana Das ${ }^{5}$, Gauri K Yadav ${ }^{6}$
}

\begin{abstract}
Introduction: Pediatric dentistry has been associated with a lot of fear of pain and anxiety in children toward dental treatment. Therefore, the stress factor is higher in children visiting dentists, and this stress may increase or decrease in the subsequent visits depending on the treatment modality they are exposed to.

Aim and objectives: The aim of this study is to assess and compare dental anxiety in pediatric patients during noninvasive dental treatment using salivary biomarkers (salivary cortisol, salivary a-amylase, and salivary immunoglobulin A (IgA)) and hemodynamic parameters. Also, to test the correlation of dental anxiety with all the biomarkers using the Corah's Dental Anxiety Scale (CDAS).

Study design: Saliva samples were collected from 60 children aged (6-12 years) with at least two or more carious lesions. The stimulated saliva samples were collected before and after treatment at the first and second appointments, respectively.

Methodology: Cardiovascular and salivary parameters including oxygen saturation, pulse rate, salivary cortisol, amylase, and lgA were assessed and co-related with the CDAS using the pulse oximeter, enzymatic method for amylase, immunoturbitidy method for IgA, and ELISA kit for salivary cortisol estimation.

Results: There was a marked increase in salivary cortisol and amylase levels in new patients, while returning patients showed even higher cortisol levels and lower amylase levels.

Conclusion: Estimation of salivary biomarkers and hemodynamic parameters proved to be an effective measure for the estimation of dental anxiety in pediatric patients.

Keywords: Dental anxiety, Hemodynamic parameters, Salivary biomarkers, Stress.

Journal of South Asian Association of Pediatric Dentistry (2019): 10.5005/jp-journals-10077-3023
\end{abstract}

\section{INTRODUCTION}

Pain and fear, likewise two sides of the coin, are important factors producing stress during dental treatment in pediatric patients. ${ }^{1}$ Measurement of stress and anxiety becomes important in pediatric patients, as this fear acquired in childhood may persist and influence adult behavior. $^{2}$

Various methods have been used so far for assessing dental fear that includes behavior rating scales, psychometric, and physiological tests. ${ }^{3}$ Since rating scales do not provide a direct viewpoint of young children as they often misinterpret drawings of facial expressions or get confused while filling the questionnaire; therefore, physiological tests and assessment of hemodynamic parameters such as elevation of heart rate and oxygen saturation level are of significant importance. ${ }^{4}$ It has been observed that stress of dental procedures may induce activation of the hypothalamuspituitary-adrenal (HPA) axis, thus, releasing different stress hormones such as cortisol. Cortisol being measurable in serum, urine, and saliva proves to be an efficient method of studying stress levels during dental procedures. Moreover, salivary samples can be easily obtained in the dental chair in which free cortisol serum levels are highly reflected. ${ }^{5}$ Few studies have been attempted to measure physiological stress induced by dental procedures and none of them have been found to assess dental anxiety involving physiological salivary biomarkers, hemodynamic parameters, and dental anxiety evaluation scales altogether in our country. Moreover, it would be a pioneer pilot study in a dental setting in Lucknow, UP. Therefore, a
1,2,5,6 Department of Pedodontics and Preventive Dentistry, Sardar Patel Post Graduate Institute of Dental and Medical Sciences, Lucknow, Uttar Pradesh, India

${ }^{3}$ Department of Oral and Maxillofacial Surgery, Sardar Patel Post Graduate Institute of Dental and Medical Sciences, Lucknow, Uttar Pradesh, India

${ }^{4}$ Department of Periodontology, Career Institute of Dental Sciences and Hospital, Lucknow, Uttar Pradesh, India

Corresponding Author: Kavita Dhinsa, Department of Pedodontics and Preventive Dentistry, Sardar Patel Post Graduate Institute of Dental and Medical Sciences, Lucknow, Uttar Pradesh, India, Phone: +91 9721222260, e-mail: grover.kavita@gmail.com

How to cite this article: Dhinsa K, Saha S, et al. Assessment and Comparison of Dental Anxiety by Measuring Physiological, Psychological and Immune Responses in Pediatric Patients Undergoing Noninvasive Dental Treatment. J South Asian Assoc Pediatr Dent 2019;2(1):14-21.

Sources of support: Estimation of salivary biomarkers done at Dr Ram Manohar Lohia Hospital, Lucknow

Conflict of interest: None

study was planned with the aim of assessing dental anxiety levels by measurement of salivary biomarkers of stress including s-cortisol, $\mathrm{s}-\lg \mathrm{A}$, and s-a amylase; correlation of physiological/hemodynamic parameters and psychological parameters (CDAS); and evaluation of level of salivary cortisol changes in children during various 
stages of dental treatment and various types of noninvasive dental procedures. Also, to evaluate factors that could affect dental anxiety in children in Lucknow, UP.

\section{Materials and Methods}

\section{Patient Selection}

A preliminary study was planned that comprised 60 children between the age group of 6 and 12 years as children above 6 years of age have developed the language of expression and would be able to read facial expressions. Study subjects were selected randomly from the Department of Pedodontics and Preventive Dentistry who had come for a routine dental treatment.

A sample size estimation was done by using the GPower software (version 3.0). It was estimated for the $F$ test and analysis of variance (ANOVA). A minimum total sample size of 31 was found to be sufficient for an $\alpha$ of 0.05 , a power of $80 \%$, and 0.4 as an effect size (assessed for salivary cortisol levels from a study conducted by Alaki et al.). ${ }^{6}$

Only those children who had no previous dental experience, with at least two simple occlusal caries not requiring local anesthesia, were selected for the study. Children less than 6 years and having a history of systemic diseases, under corticosteroid therapy, and other medically compromised conditions were excluded from the study. The clearance from the ethical committee was taken from the Institutional Ethical Committee prior to the study.

\section{Study Protocol}

The study composed of treatment in two appointments and all the appointments were scheduled mainly in the morning to avoid irrelevant stress. Also, physiological levels of cortisol are higher in mornings. In the first appointment, only oral prophylaxis was carried out followed by a restorative procedure in the second appointment. The study instructions were explained first to the child's parent and then to the child and written consent was obtained from their parents. General and medical history of the patient was taken. Parents were allowed to accompany their child during the sample collection.

During the first visit, unstimulated salivary samples were taken from all selected children. Each child was instructed to rinse his/ her mouth with water to get rid of debris, sit in an upright position, and then spit saliva in the sampling container. New patients were instructed in a similar manner to eject their salivary samples in the waiting area only and then immediately made seated on the dental chair for dental examination followed by oral prophylaxis. After the treatment was over, the child was again instructed to rinse his mouth with water to remove any fluids or debris, if present, after oral prophylaxis and spit saliva in the container (Fig. 1).

The same study subjects were called for the second appointment and were asked to eject saliva immediately after getting seated on the dental chair. Cavity preparation was done for the children followed by glass inomer cement (GIC)/composite restoration. Once the treatment was over, the child was again instructed to spit saliva in the container. The containers of saliva samples were refrigerated at $4^{\circ} \mathrm{C}$ and analyzed within 14 days. The concentration of s-cortisol, s-amylase, and s-lgA were measured by enzyme-linked immunosorbent assay (ELISA) per to the instructions from the manufacturer (Figs 2 and 3).

Apart from salivary biomarkers, hemodynamic parameters such as pulse rate and oxygen saturation were recorded prior and post-dental treatment at the first and the second appointment. The pulse oximeter was pretested in five patients prior to the conduction

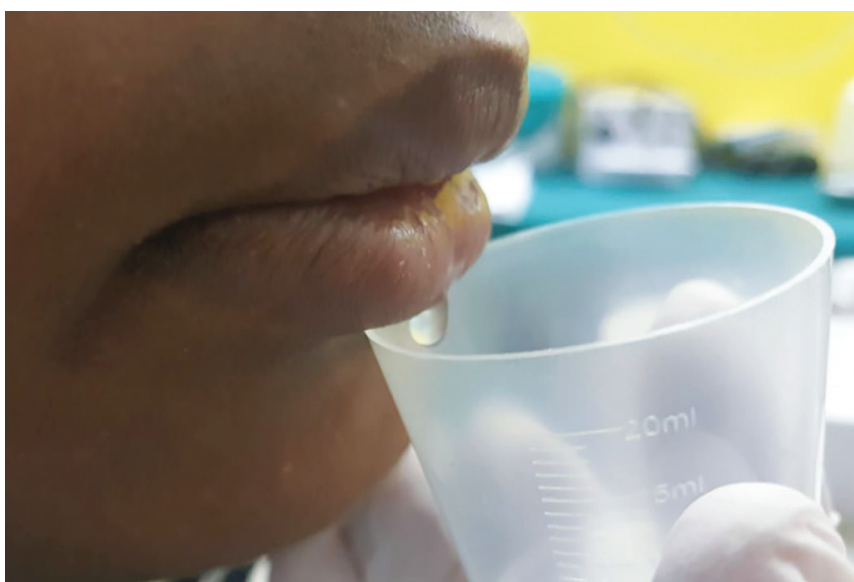

Fig. 1: Method of collection of salivary sample

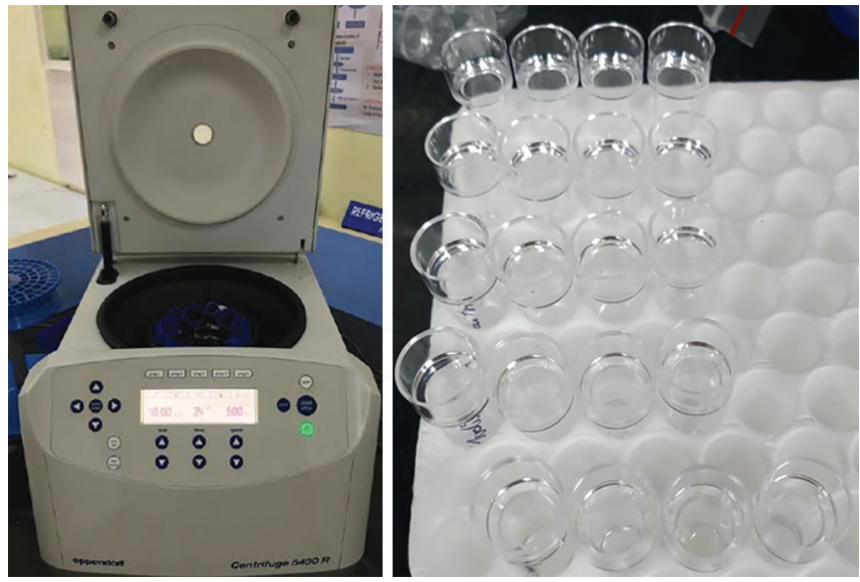

Fig. 2: Measurement of salivary cortisol level

of the main study and the readings were matched by a manual method (Fig. 4). Those five pediatric patients were excluded from the main study. Dental anxiety was recorded prior and post-dental treatment at both the appointments using the modified CDAS (Table 1 and Fig. 5). ${ }^{7}$

Data were collected, tabulated, and statistically analyzed using the GPower software (version 3.0).

\section{Results}

Total 60 pediatric patients participated in the study with a mean age of males and females were $7.4 \pm 1.27$ and $7.3 \pm 0.95$, respectively. No statistically significant difference was found in the mean ages of males and females (Table 2).

When intragroup comparison levels of stress markers were done prior and post-dental treatment at the first appointment using the Wilcoxon-signed pair rank-sum test, results revealed that there was a significant decrease in cortisol levels and anxiety post-treatment as compared prior to dental treatment, while all other parameters such as amylase level, IgA level, oxygen saturation level, and pulse rate increased significantly from pre to post (Table 3 and Fig. 6).

When intragroup comparison levels of stress markers were done prior and post-dental treatment at the second appointment using the Wilcoxon-signed pair rank-sum test, it showed that all the parameters such as cortisol level, amylase level, IgA, pulse rate, and oxygen saturation increased significantly post-dental treatment as 


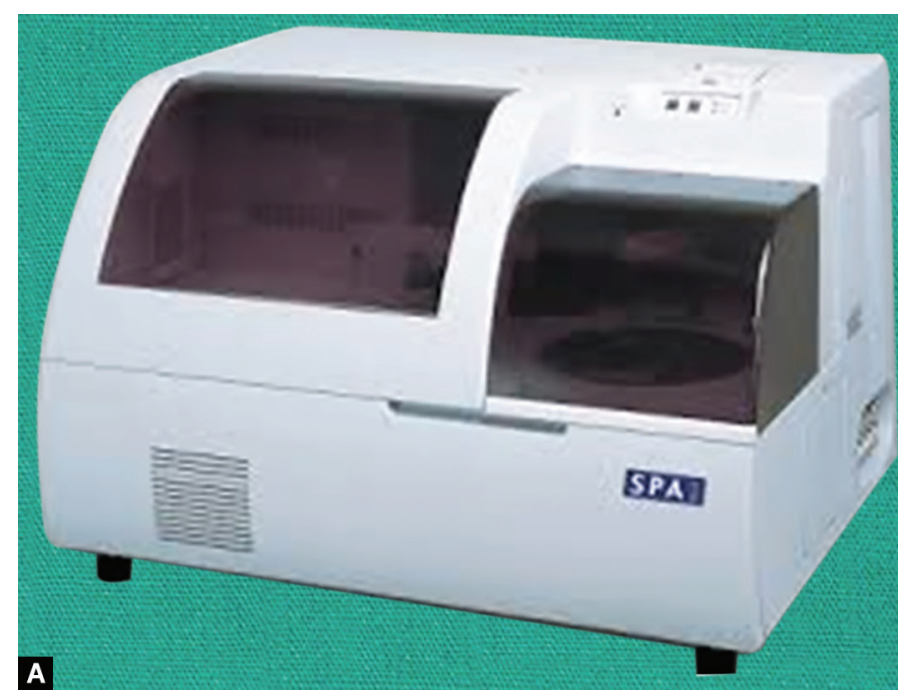

Figs $3 \mathrm{~A}$ and B: Measurement of salivary a amylase and salivary lgA level

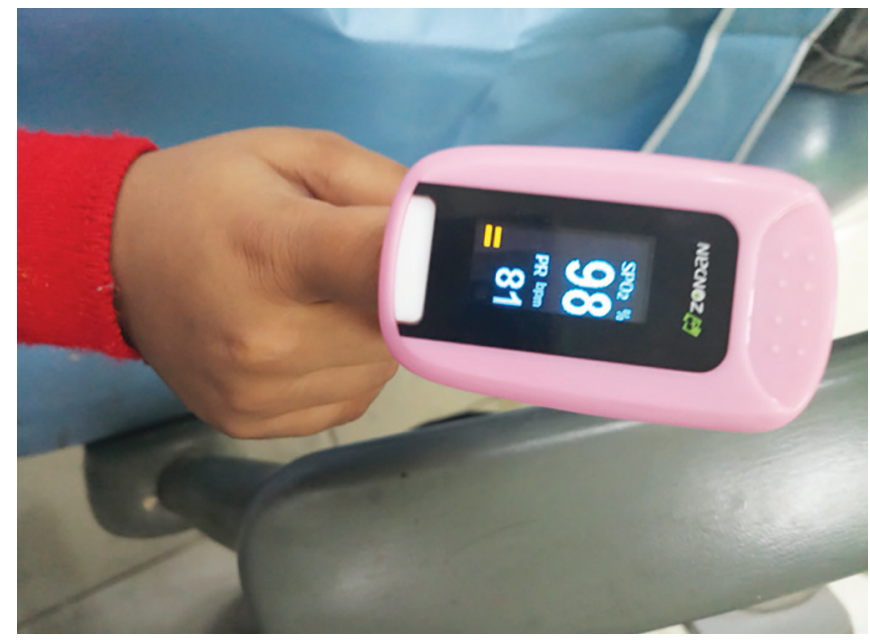

Fig. 4: Measurement of hemodynamic parameters using the pulse oximeter

Table 1: Corah's dental anxiety scale-score and severity

\begin{tabular}{ll}
\hline Score & Severity of anxiety \\
\hline $0-4$ & Patients with no fear \\
$5-8$ & Some fear \\
$9-12$ & Anxious-avoidant attitudes \\
$13-16$ & High intensity of anxiety without somatic complaints \\
$17-20$ & High intensity of anxiety and somatic symptoms \\
\hline
\end{tabular}

compared prior to the treatment. It also revealed that the anxiety level was higher prior to dental treatment as compared to postdental treatment (Table 4 and Fig. 7).

When a comparison was done between the first and the second appointment, changes among all the parameters prior to postdental treatment differed significantly (Table 5 and Fig. 8).

Prior to the first appointment, a statistically significant moderately positive correlation was found between anxiety levels and cortisol, amylase, and IgA levels, whereas a weak positive correlation was found between anxiety levels (post-) and cortisol levels but this was not statistically significant. On the other hand, no correlation could be found between anxiety and amylase and IgA levels after dental treatment of the first appointment (Table 6).

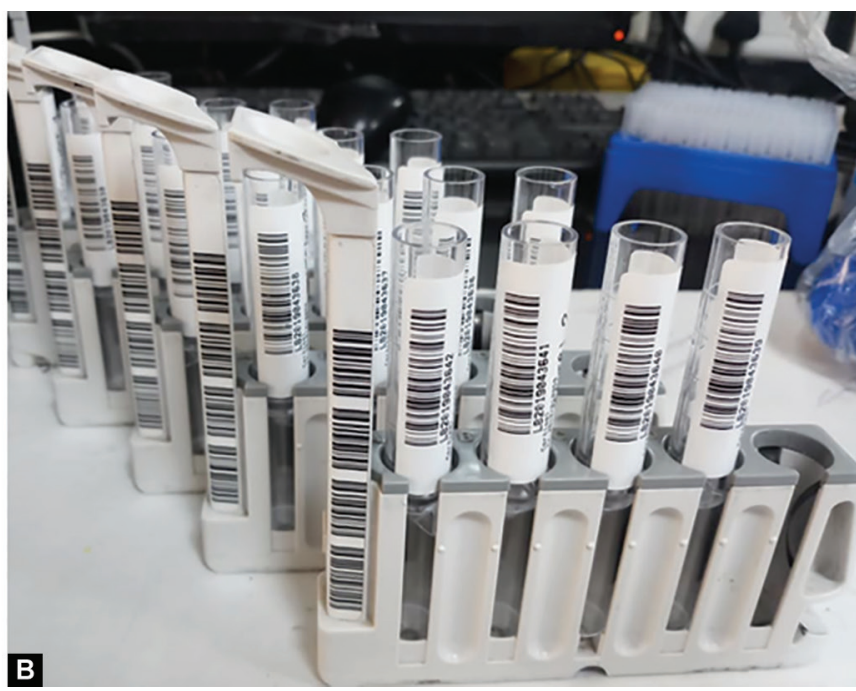

At the second appointment prior to dental treatment, a statistically significant moderately positive correlation was found between anxiety and cortisol level, whereas a weak positive correlation was seen between anxiety and amylase and IgA levels (statistically insignificant). A statistically significant moderate positive correlation was found between anxiety level and amylase level posttreatment, whereas a statistically significant strong positive correlation was found between anxiety and cortisol and IgA levels (Table 7).

\section{Discussion}

Anxiety and fear of pain during dental treatment play a crucial role in creating stress but often remain underemphasized in day-to-day dental practice. ${ }^{8}$ Somatic changes induced by dental anxiety may result in the activation of the HPA axis and the sympatho-adrenalmedullary (SAM) axis, which in turn causes the release of stress biomarkers. ${ }^{9}$ Also, the measurement of salivary concentrations allows the determination of rapid changes in the adrenocortical activities. Therefore, it has been suggested that these salivary concentrations may be also related to the level of dental anxiety.

Physiologic stress in response to stimuli is a highly subjective emotion. Physiological stress can be researched through many factors and also a lot of methods; one of them is probabilistic through statistical studies. Statistical methods can be used to see the effect of stress on physiological factors. ${ }^{10}$ Literature has also suggested that invasive techniques like venipuncture for blood sample collection raise the physiological biomarkers by inducing anxiety followed by increasing the serum cortisol levels in pediatric patients. Therefore, noninvasive methods have been preferred. ${ }^{6}$

Collection of saliva is a simple, noninvasive, and a stress-free procedure. Also, it is shown that cortisol levels in saliva closely mirror serum-free cortisol levels and are independent of the flow rate. Therefore, considering such advantages, our study included measurement of cortisol levels in saliva of pediatric patients. ${ }^{11}$ Keeping this in mind, the circadian rhythm pattern is followed by the cortisol hormone, i.e., levels being the highest in the morning; therefore, all the treatment appointments were scheduled at morning hours (9 am-11 am). Additionally, these slots were considered more favorable for the pediatric patients as well as their parents. ${ }^{12}$ 


\section{Modified Dental Anxiety Scale}

\section{Can you tell us how anxious you get, if at all, with your dental visit ? Please indicate by inserting ' $\mathrm{X}$ ' in the appropriate Box}

1. If you went to your dentist for Treatment tomorrow, how would you feel ?

$\begin{array}{lllll}\text { Not } & \text { Slightly } & \text { Fairly } & \text { Very } & \text { Extremely } \\ \text { Anxious } \square & \text { Anxious } \square & \text { Anxious } \square & \text { Anxious } \square & \text { Anxious } \square\end{array}$

1. If you were sitting in the waiting room (waiting for treatment) how would you feel?

$\begin{array}{lllll}\text { Not } & \text { Slightly } & \text { Fairly } & \text { Very } & \text { Extremely } \\ \text { Anxious } \square & \text { Anxious } \square & \text { Anxious } \square & \text { Anxious } \square & \text { Anxious }\end{array}$

1. If you were about to have a TOOTH DRILLED, how would you feel?
Not
Slightly
Fairly
Very
Extremely
Anxious

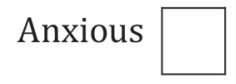
Anxious
Anxious
Anxious

1. If you were about to have a TEETH SCALED AND POLISHED, how would you feel?
Not
Slightly
Fairly
Very
Extremely
Anxious

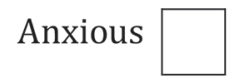
Anxious
Anxious
Anxious

1. If you were about to have a LOCAL ANESTHETIC INJECTION in your gum, above an upper black tooth, how would you feel?

\begin{tabular}{|c|c|c|c|c|}
\hline Not & Slightly & Fairly & Very & Extremely \\
\hline Anxious & Anxious & Anxious & Anxious & Anxious \\
\hline
\end{tabular}

Instructions for scoring (remove this section below before copying for use with patients)

The modified Dental Anxiety Scale, Each item scored as follows:

$\begin{array}{ll}\text { Not Anxious } & =1 \\ \text { Slightly Anxious } & =2 \\ \text { Fairly Anxious } & =3 \\ \text { Very Anxious } & =4 \\ \text { Extremely Anxious } & =5\end{array}$

Total score is a sum of all five items, range 5 to 25; Cut off is 19 or above which indicated a highly dentally anxious patient, possibly dentally phobic

Fig. 5: Corah's dental anxiety scale-questionnaire 
Table 2: Demographic information of the patients included in the study

\begin{tabular}{llllll}
\hline & Sex & $N$ & Mean & Std. deviation & $p$ value \\
\hline Age & Males & 10 & 7.40 & 1.265 & 0.882, NS \\
& Females & 10 & 7.30 & 0.949 & \\
\hline
\end{tabular}

In the present study, salivary cortisol and anxiety levels were the highest prior to dental treatment at the first appointment and reduced significantly at the end of the first appointment. This could be due to the fact that the child may be stressed in anticipation of what will happen after entering the dental examination room and being seated on the dental chair. The high level of stress causes an extreme increase in adrenal hyperactivity, which leads to increased secretion of cortisol level. Therefore, the increase in salivary cortisol level is related to the level of dental anxiety, this finding is agreed with Benjamins et al. ${ }^{13}$ There was no significant difference found in the mean cortisol level between new and the same returning patients at the second appointment, which may be explained by the fact that children tend to adapt to the stressful procedures during the second appointment. This is in accordance with the studies conducted by Benjamins et al., ${ }^{13}$ Mayer and Weber, ${ }^{12}$ Padmanabhan et al., ${ }^{14}$ and Akyuz et al., ${ }^{15}$ but this was in disagreement with a study conducted by Alaki et al., which suggested higher stress levels in children returning for the second dental visit. ${ }^{6}$
A marked significant difference was noted in the cortisol levels' posttreatment in the second appointment in which restorative procedures were done. This could be related to the unpleasant sounds of air rotor along with suction and drilling for a longer period of time. This could have resulted in an increased level of anxiety, directly elevating the levels of salivary cortisol. ${ }^{14}$

This study also showed significantly increased salivary amylase levels in patients while being seated on the dental chair. This may be attributed to the fact that the child seems to be more stressed seeing new people, strange images, unpleasant odor, dental instruments, and equipment at dental operatory. Similar results were obtained in various studies conducted by Nater and Rohleder, ${ }^{16}$ Alaki et al., ${ }^{17}$ Reis et al., ${ }^{18}$ and Alaki et al. ${ }^{6}$

A dental examination may act as a stressor which activates the autonomic nervous system leading to the release of epinephrine and norepinephrine. The latter is known to increase salivary amylase from acinar cells of the parotid and submandibular salivary glands. Salivary amylase was significantly increased in returning patients too, which may be a reflection of previous cumulative experience. ${ }^{16}$ The sound and possible discomfort with some dental procedures may have increased the stress level. Also, the new feeling caused by unknown procedures resulted in sympathetic activation. $^{18}$

Table 3: Comparison of the mean scores of salivary biomarkers pre- and posttreatment at the first appointment

\begin{tabular}{|c|c|c|c|c|c|c|}
\hline & $N$ & Minimum & Maximum & Mean & Std. deviation & $p$ value \\
\hline Cortisol 1 pre & 20 & 0.11 & 0.19 & 0.1540 & 0.03085 & $<0.0001, \mathrm{~S}$ \\
\hline Cortisol 1 post & 20 & 0.10 & 0.16 & 0.1255 & 0.02305 & \\
\hline Amylase 1 pre & 20 & 429.1 & 451.2 & 440.455 & 7.8589 & $<0.0001, \mathrm{~S}$ \\
\hline Amylase 1 post & 20 & 471.1 & 477.2 & 474.315 & 1.9778 & \\
\hline $\lg A 1$ pre & 20 & 1114.1 & 1120.3 & 1117.300 & 2.1357 & $<0.0001, \mathrm{~S}$ \\
\hline $\lg A 1$ post & 20 & 1115.2 & 1121.1 & 1118.185 & 2.0841 & \\
\hline Pulse 1 pre & 20 & 78 & 82 & 79.30 & 1.174 & $<0.0001, \mathrm{~S}$ \\
\hline Pulse 1 post & 20 & 80 & 86 & 82.10 & 2.382 & \\
\hline Oxy 1 pre & 20 & 108 & 112 & 109.70 & 1.750 & $<0.0001, \mathrm{~S}$ \\
\hline Oxy 1 post & 20 & 108 & 120 & 112.80 & 3.397 & \\
\hline Anxiety 1 pre & 20 & 4 & 5 & 4.75 & 0.444 & $<0.0001, \mathrm{~S}$ \\
\hline Anxiety 1 post & 20 & 3 & 4 & 3.85 & 0.366 & \\
\hline
\end{tabular}

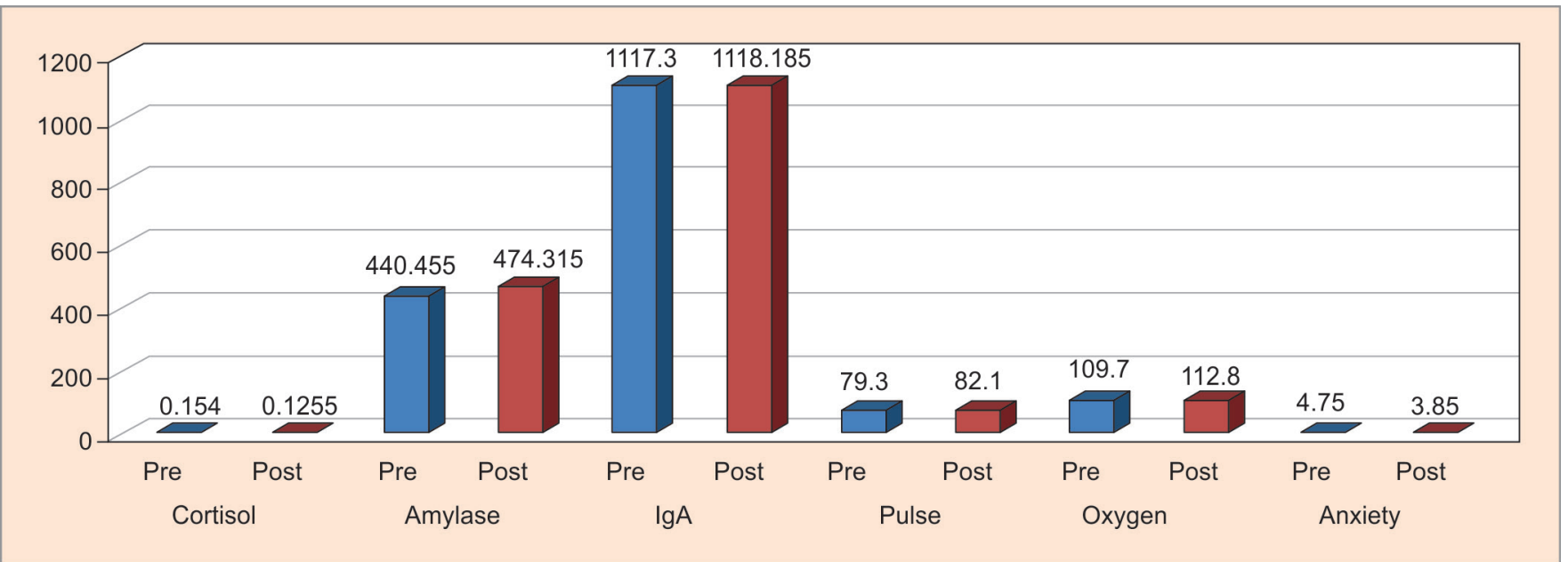

Fig. 6: Graphical representation of salivary biomarkers and hemodynamic parameters between the study group during pre- and posttreatment at the first appointment 
Assessment of Dental Anxiety with Physiological and Psychological Biomarkers in Pediatric Patients

Table 4: Comparison of the mean scores of salivary biomarkers pre- and posttreatment at the second appointment Intragroup comparison of pre and post levels of stress markers at the second appointment

\begin{tabular}{|c|c|c|c|c|c|c|}
\hline & $N$ & Minimum & Maximum & Mean & Std. deviation & $p$ value \\
\hline Cortisol 2 pre & 20 & 0.10 & 0.15 & 0.1140 & 0.01729 & $<0.0001, \mathrm{~S}$ \\
\hline Cortisol 2 post & 20 & 0.21 & 0.43 & 0.3205 & 0.06117 & \\
\hline Amylase 2 pre & 20 & 472.1 & 478.3 & 475.360 & 1.9535 & $<0.0001, \mathrm{~S}$ \\
\hline Amylase 2 post & 20 & 551.1 & 559.1 & 555.090 & 2.8168 & \\
\hline $\lg A 2$ pre & 20 & 1116.1 & 1121.7 & 1118.785 & 2.0223 & $<0.0001, \mathrm{~S}$ \\
\hline $\lg A 2$ post & 20 & 1200.6 & 1210.8 & 1206.470 & 3.2561 & \\
\hline Pulse 2 pre & 20 & 84 & 88 & 85.70 & 1.625 & $<0.0001, \mathrm{~S}$ \\
\hline Pulse 2 post & 20 & 90 & 110 & 97.50 & 8.205 & \\
\hline Oxy 2 pre & 20 & 100 & 110 & 104.50 & 3.487 & $<0.0001, \mathrm{~S}$ \\
\hline Oxy 2 post & 20 & 120 & 136 & 127.20 & 5.207 & \\
\hline Anxiety 2 pre & 20 & 4 & 5 & 4.20 & 0.410 & 0.180, NS \\
\hline Anxiety 2 post & 20 & 4 & 5 & 4.35 & 0.489 & \\
\hline
\end{tabular}

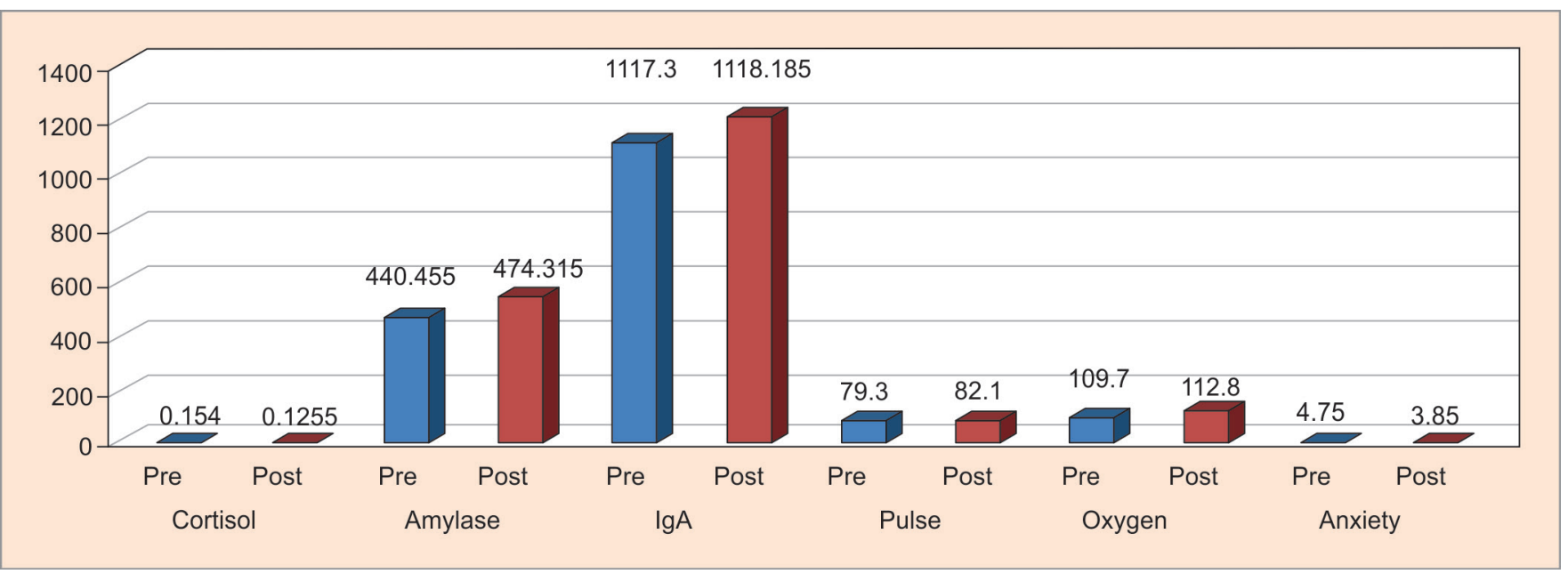

Fig. 7: Graphical representation of salivary biomarkers and hemodynamic parameters between the study group during pre- and posttreatment at the second appointment

Table 5: Comparison of the mean scores of salivary biomarkers pre- and posttreatment between the first and the second appointment

\begin{tabular}{|c|c|c|c|c|c|c|}
\hline & $N$ & Minimum & Maximum & Mean & Std. deviation & $p$ value \\
\hline Diff. cortisol 1 & 20 & 0.00 & 0.05 & 0.0285 & 0.01496 & $<0.0001, \mathrm{~S}$ \\
\hline Diff. cortisol 2 & 20 & -0.30 & -0.11 & -0.2065 & 0.05163 & \\
\hline Diff. amylase 1 & 20 & -43.00 & -24.30 & -33.8600 & 6.27429 & $<0.0001, \mathrm{~S}$ \\
\hline Diff. amylase 2 & 20 & -82.00 & -77.00 & -79.7300 & 1.41722 & \\
\hline Diff. IgA 1 & 20 & -2.00 & -0.20 & -0.8850 & 0.43198 & $<0.0001, \mathrm{~S}$ \\
\hline Diff. $\lg A 2$ & 20 & -92.90 & -84.20 & -87.6850 & 2.26908 & \\
\hline Diff. pulse 1 & 20 & -6.00 & 0.00 & -2.8000 & 1.76516 & $<0.0001, S$ \\
\hline Diff. pulse 2 & 20 & -24.00 & -4.00 & -11.8000 & 7.19356 & \\
\hline Diff. Oxy 1 & 20 & -8.00 & 0.00 & -3.1000 & 1.99737 & $<0.0001, \mathrm{~S}$ \\
\hline Diff. Oxy 2 & 20 & -30.00 & -16.00 & -22.7000 & 3.96166 & \\
\hline Diff. anxiety 1 & 20 & 0.00 & 2.00 & 0.9000 & 0.44721 & $<0.0001, \mathrm{~S}$ \\
\hline Diff. anxiety 2 & 20 & -1.00 & 1.00 & -0.1500 & 0.48936 & \\
\hline
\end{tabular}

The higher levels of salivary $\lg A$ were also found reflecting the adaptive physiological responses of the children to previous cumulative experience. Higher concentrations of s-IgA in children with caries were obtained which may be due to increased antigenic load, leading to high production of antibodies. These results were too in agreement with studies produced by Al Amoudi et al. ${ }^{19}$ and Alaki et al. ${ }^{6}$

Other physiologic parameters such as oxygen saturation and pulse rate increased significantly from the first appointment to the second appointment. Dental anxiety may be the reason for such an 


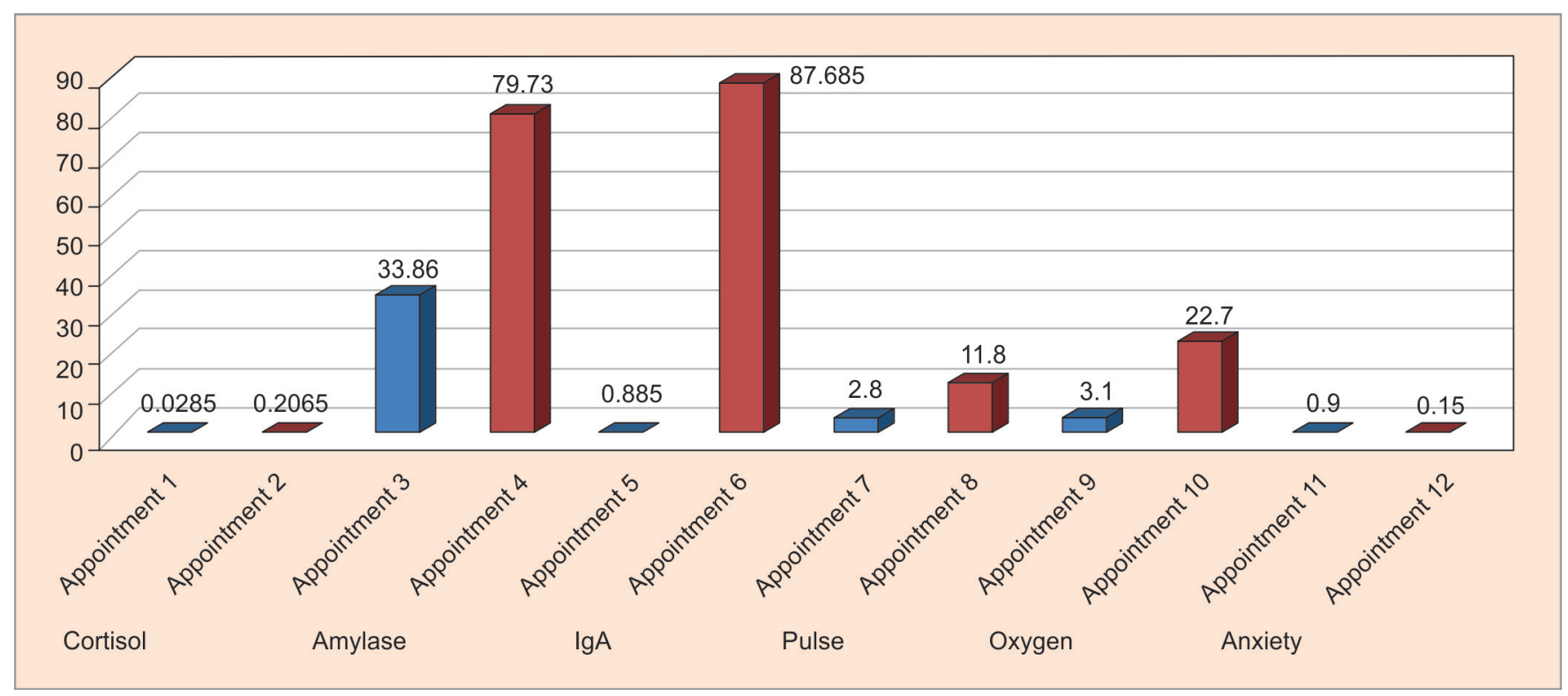

Fig. 8: Graphical representation showing comparison of the mean scores of salivary biomarkers pre- and posttreatment between the first and the second appointment

Table 6: Correlation of dental anxiety and salivary biomarkers pre- and posttreatment at the first appointment

\begin{tabular}{|c|c|c|c|c|}
\hline & & $\begin{array}{l}\text { Cortisol } \\
\text { pre }\end{array}$ & $\begin{array}{l}\text { Amylase } \\
\text { pre }\end{array}$ & IgA pre \\
\hline \multirow{3}{*}{$\begin{array}{l}\text { Correlation of } \\
\text { anxiety level } \\
\text { (pre-) at the first } \\
\text { appointment }\end{array}$} & $\begin{array}{l}\text { Spearman } \\
\text { correlation } \\
\text { coefficient }\end{array}$ & 0.577 & 0.571 & 0.572 \\
\hline & $p$ value & $0.033, \mathrm{~S}$ & $0.009, \mathrm{~S}$ & $0.008, \mathrm{~S}$ \\
\hline & & $\begin{array}{l}\text { Cortisol } \\
\text { post }\end{array}$ & $\begin{array}{l}\text { Amylase } \\
\text { post }\end{array}$ & $\lg A$ post \\
\hline \multirow{2}{*}{$\begin{array}{l}\text { Correlation of } \\
\text { anxiety level } \\
\text { (post-) at the first } \\
\text { appointment }\end{array}$} & $\begin{array}{l}\text { Spearman } \\
\text { correlation } \\
\text { coefficient }\end{array}$ & 0.123 & -0.036 & 0.097 \\
\hline & $p$ value & 0.604, NS & 0.879, NS & $0.683, \mathrm{NS}$ \\
\hline
\end{tabular}

Table 7: Correlation of dental anxiety and salivary biomarkers pre- and posttreatment at the second appointment

\begin{tabular}{lllll}
\hline & & $\begin{array}{l}\text { Cortisol } \\
\text { pre }\end{array}$ & $\begin{array}{l}\text { Amylase } \\
\text { pre }\end{array}$ & IgA pre \\
\hline $\begin{array}{l}\text { Correlation of anxiety } \\
\text { level (pre-) at the } \\
\text { second appointment }\end{array}$ & $\begin{array}{l}\text { Spearman } \\
\text { correlation } \\
\text { coefficient } \\
p \text { value }\end{array}$ & 0.457 & 0.142 & 0.369 \\
& & $0.043, \mathrm{~S}$ & $0.550, \mathrm{NS}$ & $0.109, \mathrm{NS}$ \\
\hline & & $\begin{array}{l}\text { Cortisol } \\
\text { post }\end{array}$ & $\begin{array}{l}\text { Amylase } \\
\text { post }\end{array}$ & IgA post \\
\hline $\begin{array}{l}\text { Correlation of anxiety } \\
\text { level (post-) at the } \\
\text { second appointment }\end{array}$ & $\begin{array}{l}\text { Spearman } \\
\text { correlation } \\
\text { coefficient }\end{array}$ & 0.677 & 0.574 & 0.655 \\
& $p$ value & $0.001, \mathrm{~S}$ & $0.008, \mathrm{~S}$ & $0.002, \mathrm{~S}$ \\
\hline
\end{tabular}

increase in the pulse rate. Also, an increase in the pulse rate varies due to the physical movement of the individual during dental treatment. Our study results were in accordance with Liau et al., ${ }^{20}$ Agani et al., ${ }^{21}$ and Gadicherla et al. ${ }^{22}$

\section{Conclusion}

The study focuses on the importance of monitoring the stress levels in pediatric patients during dental treatment using salivary biomarkers and hemodynamic parameters along with dental anxiety. Estimation of salivary cortisol levels with amylase and other physiologic parameters proved to be valid and effective in assessing dental anxiety in children. Thus, a rapid evaluation of these biomarkers could help to monitor stress among pediatric patients thereby reducing the fear and anxiety while undergoing dental treatment.

\section{LIMITATIONS}

Sample collection of saliva for estimating salivary biomarkers is easy to perform but requires laboratory support which may not be possible for all clinical and practice situations.

\section{ACKNOWLEDgments}

Authors would like to extend their gratitude to the staff of Dr Ram Manohar Lohia Hospital and Dr Ruchi Nagpal for their valuable insight and helping in conduction of this study.

\section{References}

1. Pinkham JR. Patient management. Pediatric Dentistry. In: Pinkham JR, ed. Philadelphia: WB Saunders Co.; 1988. pp. 269-281.

2. Milgrom $P$, Weinstein $P$. Dental fears in general practice: new guidelines for assessment and treatment. Int Dent J 1993;43: 288-293.

3. Radis FG, Wilson S, etal.Temperament as a prediction of behaviour during initial dental examination in children. Pediatr Dent 1994;16:121-127.

4. Irwin M, Hauger RL. Developmental aspects of psychoneuroimmunology. Child and Adoloscent, Psychiatry: A Comprehensive Textbook. In: Lewis M, ed. Williams and Wikins; 1991. pp. 51-62.

5. Burtis C, Ashwood ER. Function of the adrenal cortex. Tietz textbook of clinical chemistry. In: 3rd ed., 1999; pp. 1559-1560; ch. 43.

6. Alaki SM, Safi A, et al. Nadhreen. Comparing Dental Stress in New Child Patients and Returning Patients Using Salivary 
Cortisol, Immunoglobulin-A and Alpha-Amylase. J ClinPed Dent 2017;41(6):462-466.

7. Corah NL. Development of dental anxiety scale. J Dent Res 1969;48:59-60. DOI: 10.1177/00220345690480041801.

8. Wright GZ. Behaviour Management in Dentistry for Children. Philadelphia. Philadelphia, PA: WB Saunders Co.; 1975.

9. Gusenoff JA, Harman M, et al. Cortisol and GH Secretory dynamics, and their interrelationships, in healthy aged women and men. Am J Physiol Endocrinol Metab 2001;280:E616-E625. DOI: 10.1152/ ajpendo.2001.280.4.E616.

10. Sari SIK. Influence of Stress on Blood Pressure, Heart Rate, Levels of Salivary Amylase and Skin Temperature. J Eng Manag Ind Sys 2016;4(2):109-120.

11. Greenwood PL, Shutt DA. Salivary and Plasma Cortisol as an index of stress in goats. Aust Vet J 1992;69:161-163. DOI: 10.1111/j.17510813.1992.tb07501.x.

12. Mayer R, Weber E. Kinderbehandlung in der zahnartlichen Praxis Bestimmung des Stresshormons Cortisol imSpeichel. Quintessenz 1992;43:993-996.

13. Benjamins $\mathrm{C}$, Asscheman $\mathrm{H}$, et al. Increased Salivary Cortisol in Severe Dental Anxiety. Psychopysiology 1992;29:302-305. DOI: 10.1111/j.1469-8986.1992.tb01703.x.

14. Padmanabhan V, Rai K, et al. Stress responses in children during endodontic treatment. J Ped Dent 2013;1(1):14-18. DOI: 10.4103/23216646.113851 .
15. Akyuz $S$, Pince $S$, et al. Children's stress during a restorative dental treatment: assessment using salivary cortisol measurements. J ClinPed Dent 1996;20(3):219-223.

16. Nater UM, Rohleder N. Salivary alpha-Amylase as a non-invasive biomarker for the sympathetic nervous system: current state of research. Psychoneurendocrinol 2009;34(4):486-496. DOI: 10.1016/j. psyneuen.2009.01.014.

17. Alaki S, Alotaibi A, et al. Dental anxiety in middle school children and their caregivers. Prevalence and Severity. J Dent and Oral Hyg 2012;4(1):6-11.

18. Reis AC, Sanchotene MC, et al. Levels of Anxiety and Salivary AlphaAmylase in Children During Restorative Dental Treatment. Braz Res Ped Dent Int Clin 2016;16(1):499-509. DOI: 10.4034/PBOCI.2016.161.52.

19. Al Amoudi $\mathrm{N}, \mathrm{Al}$ Shukairy $\mathrm{H}$, et al. A comparative study of the secretory $\lg A$ immunoglobulins in mothers and children with SECC vs a caries free group children and their mothers. J Clin Pediatr Dent 2007;32:53-56. DOI: 10.17796/jcpd.32.1.I338366jw54634q5.

20. Liau F, Kuo R, et al. Cardiovascular influence of dental anxiety during local anesthesia for tooth extraction. Oral Surg Oral Med Oral Pathol Oral Radiol Endod 2008;105:16-26. DOI: 10.1016/j.tripleo.2007.03.015.

21. Agani ZB, Benedetti $A$, et al. Cortisol Level and Hemodynamic Changes During Tooth Extraction at Hypertensive and Normotensive Patients. Med Arch 2015;69:117-122. DOI: 10.5455/medarh.2015.117-122.

22. Gadicherla S, Shenoy RP, et al. Estimation of Salivary Cortisol among Subjects Undergoing Dental Extraction. J ClinExp Dent 2018;10(2):e116-e119. DOI: 10.4317/jced.54369. 